\title{
Single Ascending Dose Study to Assess Pharmacokinetic Linearity, Safety, and Tolerability of Trimetazidine - Modified Release in Healthy Human Subjects
}

\author{
Authors \\ Stella Böhmert ${ }^{6}$, Rita Silveira Ramos ${ }^{7}$, Shashank Jain²

\section{Affiliations} \\ 1 Parexel International GmbH, Berlin, Germany \\ 2 Drug Safety and Risk Management, Lupin Limited (India), \\ Mumbai, India \\ 3 Teva Pharmaceutical Industries LTD, Petach Tikva, Israel \\ 4 Department of Clinical Research, Gedeon Richter Plc. \\ Budapest, Hungary \\ 5 Clinical Development Mylan EPD, Amstelveen, the \\ Netherlands \\ 6 Sandoz International GmbH, Holzkirchen, Germany \\ 7 Generis ${ }^{\circledR}$ Farmacêutica, Amadora, Portugal
}

Thomas Körnicke1, Deepa Arora², Abdus Samad², Sigal Kaplan³, Mónika Domahidy4, Hanka de Voogd ${ }^{5}$,

\section{Key words}

pharmacokinetics, drug delivery, drug research, clinical trials, cardiovascular pharmacology

received 25.02 .2020

accepted 27.03.2020

Published online: 4.9.2020

Bibliography

Drug Res 2020; 70: 472-477

DOI 10.1055/a-1180-4357

ISSN 2194-9379

(c) 2020. Thieme. All rights reserved.

Georg Thieme Verlag KG, Rüdigerstraße 14,

70469 Stuttgart, Germany

\section{Correspondence}

Shashank Jain PhD

Drug Safety and Risk Management

Lupin Limited

Kalpataru Inspire, 5th Floor, Off Western

Express Highway,

Santacruz (East), Mumbai 400055

India

Tel.: + 91-22-66402730

shashankslrd@gmail.com

\section{ABSTRACT}

Aim This study assessed the linearity of pharmacokinetics (PK) of trimetazidine (TMZ) modified-release tablets (indicated in adults as an add-on therapy for stable angina pectoris) and measured its renal elimination, safety, and tolerability in healthy subjects.

Methods This was a randomized, open-label, single-ascending dose study in healthy subjects. Subjects were administered with a single dose of 35,70 , or $105 \mathrm{mg}$ TMZ-modified release tablets (six subjects each). Pharmacokinetic evaluations and safety analysis were performed before the first dose and till $48 \mathrm{~h}$ post-first dose.

Results Following administration of 35,70 , and $105 \mathrm{mg} \mathrm{TMZ-}$ modified release; the $C_{\max }$ (mean $\left.\pm S D\right)$ was $79.32( \pm 23.08)$, $153.17( \pm 23.08)$, and $199.67( \pm 23.08) \mathrm{ng} / \mathrm{mL}$, the $T_{\max }$ was $5.42( \pm 0.49), 4.51( \pm 1.27)$, and $4.57( \pm 0.96) h, t_{1 / 2}$ was 7.75 ( \pm 1.62$), 6.40( \pm 1.23)$, and $6.50( \pm 1.18) \mathrm{h}, \mathrm{AUC}_{(0 \text {-inf })}$ was $1116.89( \pm 378.35), 1838.39( \pm 284.50)$, and 2504.84 $( \pm 348.35) \mathrm{ng} . \mathrm{h} / \mathrm{mL}, \mathrm{CL}_{R}$ was $13.70( \pm 2.24), 14.80( \pm 5.91)$, and $19.58( \pm 6.24) \mathrm{L} \cdot \mathrm{h}^{-1}$ and CL/F was $33.69( \pm 8.51), 38.85$ $( \pm 6.15)$, and $42.74( \pm 7.10) \mathrm{L} \cdot \mathrm{h}^{-1}$, respectively. Slope estimates for $A U C_{(0-\text { inf })}, A U C_{(0-\mathrm{t})}$, and $C_{\max }$ were less than 1. Corresponding $95 \% \mathrm{Cl}$ of the slope for the AUC parameters excluded 1 , indicating that the deviation from dose-proportionality was statistically significant. Corresponding $95 \% \mathrm{Cl}$ of the slope for $\mathrm{C}_{\max }$ included 1, indicating that the less than dose-proportional increase in $C_{\max }$ was not statistically significant. No significant adverse events were observed.

Conclusion Substantial deviation from a dose-proportional increase in $\mathrm{AUC}_{(0 \text {-inf) }}$ and $\mathrm{AUC}_{(0-\mathrm{t})}$ suggested a non-linear PK for TMZ-modified release. Single dose of TMZ-modified release was well tolerated and safe.

\section{Introduction}

Trimetazidine (TMZ), an anti-ischemic and anti-anginal metabolic agent, is indicated in adults as an add-on therapy for the sympto- matic treatment of patients with stable angina pectoris who are inadequately controlled by or intolerant to first-line anti-anginal therapies. Its modified release (MR) tablet is recommended as TMZ 
$35 \mathrm{mg}$ tablet to administer twice daily. The pharmacokinetics (PK) of TMZ is described in the product labeling [1]. Elimination of TMZ has been found to be predominantly renal with $79-84 \%$ of administered radioactivity appearing in the urine within $24 \mathrm{~h}$, of which at least $60 \%$ was due to unchanged TMZ [2]. Yet, there is limited knowledge on the PK of TMZ in both the elderly and in subjects with renal function impairment. The effect of age and renal function on the PK profile of the modified release (MR) tablet of TMZ $35 \mathrm{mg}$ administered twice daily has been studied previously [3]. TMZ renal clearance was approximately $25.2 \mathrm{~L} / \mathrm{h}\left(420 \mathrm{~mL} \mathrm{~min}^{-1}\right)$ in subjects with normal renal function, 3.5-fold higher than the glomerular filtration rate (GFR). The high renal clearance as a result of the relatively low plasma protein binding of TMZ (15\%) suggests a significant renal tubular secretion. Moreover, it has been observed that stable angina pectoris, for which TMZ is indicated, is more frequent in the elderly and impaired kidney function patients. Given the role of the kidneys in the pharmacokinetics (PK) and specifically the clearance of TMZ, further evaluation of the target population for $\mathrm{TMZ}$, i.e., elderly and patients with impaired kidney function, is needed for any potential dosing adjustment $[3,4]$.

In 2011, TMZ was subjected to an Article 31 Referral procedure in Europe, initiated by the French Health products Agency (AFSSAPS, now ANSM) at the European Medicines agency (EMA) due to both efficacy and safety concerns (including Parkinson's syndrome and lack of data in frail target populations) [5]. After the review, the Committee for Medicinal Products for Human Use (CHMP) requested that "The MAH should perform a PK study assessing the effect of renal impairment and age on TMZ PK according to the CHMP agreed protocol" as data were lacking in these subject groups because the elderly (above 65 and even 75 years of age) were an important target population for treatment with TMZ. However, the linearity of PK of trimetazidine had not been established. Thus, as a first step we conducted the current single ascending dose study to assess linearity of PK of trimetazidine. We conducted this study in healthy subjects with various dosage regimen to assess linearity of PK of TMZ-modified release. Based on the results of current study, we also conducted a multiple-dose to evaluate the effect of age and renal impairment on the pharmacokinetics of trimetazidine (TMZ) in healthy elderly and renally-impaired subjects and to assess its safety and tolerability profile. Results of the multiple-dose study have been published elsewhere[6].

Therefore, the current study was conducted in accordance with the CHMP requirements to evaluate PK and safety of TMZ. Specifically, the objectives of this study were to assess: (1) linearity of PK of TMZ-modified release, and (2) the safety and tolerability of TMZ in healthy subjects.

\section{Methods}

\section{Study Design}

This was a randomized, open-label, single ascending-dose study. Eighteen healthy subjects of any gender of 18-55 years of age with normal renal function were enrolled. Subjects were screened within 2 months of admission. Sample size was determined based on 'the evaluation of the 'Pharmacokinetics of medicinal products in patients with decreased renal function EMA/83874/2014.' Subjects were included in this study if they had no clinically relevant abnormalities identified by a detailed medical history, full physical examination, blood pressure (BP), pulse measurements, temperature, respiratory rate (RR), height, weight, 12-lead electrocardiogram (ECG), and clinical laboratory tests. Subjects were excluded from the study if they had a condition that could be affected by participation in the study or by administration of TMZ-modified release or might interfere with the interpretation of the study. Subjects with hypersensitivity to TMZ, excipients, any structurally related drugs and/or any excipient were also excluded. No concomitant medications were allowed during the study, except for hormone replacement therapy and/or paracetamol (up to $1 \mathrm{~g} /$ day for analgesia). The eligibility status of the participants was reconfirmed on the day before the study. This joint study was sponsored by a consortium of TMZ Marketing Authorization Holders in the European Union. All study procedures were conducted in accordance with the ethical principles of Good Clinical Practice (GCP) and the Declaration of Helsinki. An Independent Ethics Committee reviewed and approved the study protocol and informed consent form before participants were screened. All participants provided written informed consent before admission to the study.

\section{Intervention and posology}

The 18 study subjects were randomly assigned to 3 parallel cohorts of 6 subjects each to receive a single ascending dose of $35,70 \mathrm{mg}$ or 105 of oral TMZ-modified release tablet. According to SmPC (summary of product characteristics) for trimetazidine, the normal dose for trimetazidine for adult is $35 \mathrm{mg}$ twice a day. Based on this standard dosing, we selected these single doses. The study medication was provided as the branded Moduxin ${ }^{\circledR}$ MR $35 \mathrm{mg}$, retard tablet (manufactured by Gedeon Richter, Romania). The tablets were administered orally at scheduled dosing time in sitting position with $240 \mathrm{~mL}$ of drinking water and standard breakfast (single dosing).

\section{Pharmacokinetic evaluation}

Blood samples $(4 \mathrm{~mL})$ were collected before dosing and at 1, 2, 2.5, 3, 3.5, 4, 4.5, 5, 5.5, 6, 7, 8, 10, 12, 24, 36, and $48 \mathrm{~h}$ after dosing. Drug administration and blood sampling processes were under continuous medical supervision. Collected blood samples were centrifuged at $3000 \mathrm{~g}$ for $10 \mathrm{~min}$. The plasma was separated and stored at approximately $-20^{\circ} \mathrm{C}$ for further analysis. Quantification of trimetazidine in plasma samples was carried out using analytical assay method of High-Performance Liquid Chromatography (HPLC) with Tandem Mass Spectrometer (MS/MS) detection which was developed and validated before the start of the clinical study. This method was developed for a concentration range spanning the TMZ levels from $4.8-28.0 \mu \mathrm{g} / \mathrm{mL}$ which was expected to be present in the plasma samples collected during the clinical study. Blood and urine samples were also analysed in central laboratory to measure clinical laboratory parameters.

The pharmacokinetic parameters of TMZ were calculated by non-compartmental analysis methods using Phoenix ${ }^{\circledR}$ WinNonlin ${ }^{\circledR}$ software, version 6.3. Actual sampling times relative to dosing rather than nominal times were used in the calculation of all derived PK parameters. There was no imputation of missing data. Pharmacokinetic parameters evaluated were: area under the plasma concen- 
tration-time curve from time 0 to the last quantifiable concentration $\left(A \cup C_{(0-t)}\right)$, area under the plasma concentration-time curve from time 0 to $\infty$ was calculated as $A U C_{(0-\text { inf })}=A U C_{(0-t)}+C_{\text {last } /} \lambda_{z}$, where $C_{\text {last }}$ was the last quantifiable plasma concentration and $\lambda_{z}$ was the apparent terminal elimination rate constant $\left(A \cup C_{(0 \text {-inf })}\right)$, apparent total body clearance (CL/F) and maximum observed plasma concentration $\left(C_{\max }\right)$ were used for the assessment of linearity. Secondary endpoints included the renal elimination of TMZ (renal clearance $\left[\mathrm{CL}_{R}\right]$ ) and safety parameters. Pharmacokinetic concentration data were listed by subject including actual sampling times relative to dosing. Plasma and urine concentrations were analyzed by analyte (TMZ), intervention group/cohort, and nominal time point. Descriptive statistics of PK parameters for plasma concentrations obtained at each nominal time point were summarized by intervention group/cohort. Coefficient of variation (CV\%), and geometric CV\% (calculated as: gCV\% $=S Q R T\left[\exp \left(S^{2}\right)-1\right]$ * 100; where $\mathrm{SD}=$ standard deviation of the natural-logarithmically-transformed data) values were calculated. Mean plasma concentrations versus nominal times were also presented in a linear and semi-logarithmic scale. To confirm renal function in these healthy subjects, renal function was assessed by estimating creatinine clearance (from serum creatinine [Scr]) using the Modification of Diet in Renal Disease (MDRD) approach, prior to enrollment or screening period [7].

The MDRD formula was:

eGFR $\left(\mathrm{mL} / \mathrm{min} / 1.73 \mathrm{~m}^{2}\right)=175 \times(\mathrm{Scr}, \mathrm{std})^{-1.154}(\text { Age })^{-0.203 \times}$ (0.742 if female $) \times(1.212$ if African American $)$

\section{Assessment of Dose-Proportionality}

Dose-proportionality was assessed for $C_{\max }, A \cup C_{(0-t)}$ and $A U C_{(0-i n f)}$ using the following power model:

In $<$ Parameter $>=\alpha+\beta$ In $<$ Dose $>$

When both sides are exponentiated:

$<$ Parameter $>=\exp (\alpha) \cdot<$ Dose $>\beta$

Thus, when $\beta=1$, the drug is proportional.

Actual and planned dose values were used in the analyses. The parameter estimates for $\beta$ and $95 \%$ confidence interval were presented to assess dose-proportionality. No inferential analysis was performed other than the dose-proportionality analysis.

\section{Safety evaluation}

Numbers of Treatment-emergent adverse events (TEAEs) were summarized by System Organ Class (SOC) and preferred term and severity/causality to the study drug. The following safety variables were assessed: physical examination, vital signs (BP, pulse, oral temperature, respiratory rate (RR) measured in breaths per minute, 12 lead ECG in triplicate, haematology (red blood cell count, mean corpuscular volume [MCV]), mean corpuscular haemoglobin, haemoglobin, haematocrit, platelet count, white blood cell count and differentials (neutrophils, eosinophils, basophils, lymphocytes, monocytes), biochemistry (magnesium, sodium, potassium, chloride, creatinine, creatine phosphokinase, glucose, urea, uric acid, calcium, inorganic phosphorus, alkaline phosphatase [AP], Aspartate aminotransferase [AST], Alanine aminotransferase [ALT], gamma-glutamyl transferase, total bilirubin, total protein, albumin, total cholesterol and triglycerides), and urine analysis. A midstream, clean-catch urine specimen was collected for dipstick analysis of bilirubin, protein, blood, glucose, nitrite, ketone, and $\mathrm{pH}$. Urine samples positive for blood or protein, were sent for microscopy if deemed appropriate by the investigator. Pregnancy, adverse events (AEs), and QTc interval were also recorded. The grading and reporting of $A E$ were performed according to Common Terminology Criteria for Adverse Events (CTCAE).

\section{Results}

\section{Demographics}

Of the 51 subjects who were screened in the study, 18 subjects met all the study eligibility criteria and completed treatment and follow-up ( $\triangleright$ Table 1). Most of the subjects in the study were female (72.2\%), Caucasian (94.4\%) and aged between 19 and 51 years. In the 35 -mg dose group, all the subjects were females.

\section{TMZ pharmacokinetic analysis}

The arithmetic mean maximum plasma concentration $\left(C_{\max }\right)$ of TMZ-modified release following a single-dose of 35,70 , and $105 \mathrm{mg}$ was $79.32( \pm 23.08), 153.172( \pm 23.08)$, and $199.677( \pm 23.08) \mathrm{ng} /$ $\mathrm{mL}$, respectively ( $\triangleright$ Fig. 1 ). The corresponding median time to $C_{\max }$ $\left(T_{\max }\right)$ was comparable across the dose range investigated [5.42 ( \pm 0.49$), 4.51$ ( \pm 1.27$)$, and 4.57 ( \pm 0.96$)$, respectively] ( Table 2 ).

- Table 1 Subject demographics.

\begin{tabular}{|c|c|c|c|c|}
\hline \multirow[b]{2}{*}{ Parameter } & \multicolumn{3}{|c|}{ Intervention group } & \multirow{2}{*}{$\begin{array}{l}\text { Total } \\
\mathrm{N}=18\end{array}$} \\
\hline & $\begin{array}{l}35 \mathrm{mg} \\
(\mathrm{n}=6)\end{array}$ & $\begin{array}{l}70 \mathrm{mg} \\
(\mathrm{n}=6)\end{array}$ & $\begin{array}{l}105 \mathrm{mg} \\
(\mathrm{n}=6)\end{array}$ & \\
\hline \multicolumn{5}{|l|}{ Age (years) } \\
\hline Mean ( $\pm S D)$ & $\begin{array}{l}38.5 \\
( \pm 12.39)\end{array}$ & $\begin{array}{l}29.2 \\
( \pm 8.91)\end{array}$ & $\begin{array}{l}34.8 \\
( \pm 11.05)\end{array}$ & $\begin{array}{l}34.2 \\
( \pm 10.96)\end{array}$ \\
\hline \multicolumn{5}{|l|}{ Gender } \\
\hline Male & 0 & $2(33.3 \%)$ & $3(50.0 \%)$ & $5(27.8 \%)$ \\
\hline Female & $6(100 \%)$ & $4(66.7 \%)$ & $3(50.0 \%)$ & $13(72.2 \%)$ \\
\hline \multicolumn{5}{|l|}{ Race } \\
\hline Caucasian & $6(100 \%)$ & $5(83.3 \%)$ & $6(100 \%)$ & $17(94.4 \%)$ \\
\hline $\begin{array}{l}\text { American } \\
\text { Indian or } \\
\text { Alaska Native }\end{array}$ & 0 & $1(16.7 \%)$ & 0 & $1(5.6 \%)$ \\
\hline \multicolumn{5}{|l|}{ Height (cm) } \\
\hline Mean ( \pm SD) & $\begin{array}{l}163.2 \\
( \pm 4.26)\end{array}$ & $\begin{array}{l}167.5 \\
( \pm 13.37)\end{array}$ & $\begin{array}{l}177.5 \\
( \pm 10.48)\end{array}$ & $\begin{array}{l}169.4 \\
( \pm 11.33)\end{array}$ \\
\hline \multicolumn{5}{|l|}{ Weight (kg) } \\
\hline Mean ( $\pm S D)$ & $\begin{array}{l}60.18 \\
( \pm 6.1)\end{array}$ & $\begin{array}{l}61.35 \\
( \pm 12.68)\end{array}$ & $\begin{array}{l}73.50 \\
( \pm 14.27)\end{array}$ & $\begin{array}{l}65.01 \\
( \pm 12.51)\end{array}$ \\
\hline \multicolumn{5}{|l|}{ BMI $\left(\mathbf{k g} \cdot \mathbf{m}^{-2}\right)$} \\
\hline Mean $( \pm S D)$ & $\begin{array}{l}22.57 \\
( \pm 1.64)\end{array}$ & $\begin{array}{l}21.68 \\
( \pm 1.98)\end{array}$ & $\begin{array}{l}23.13 \\
( \pm 2.69)\end{array}$ & $\begin{array}{l}22.46 \\
( \pm 2.11)\end{array}$ \\
\hline \multicolumn{5}{|c|}{ Serum Creatinine $\left(\mathbf{m g} \cdot \mathrm{L}^{-1}\right)$} \\
\hline Mean $( \pm S D)$ & $\begin{array}{l}57.00 \\
( \pm 7.3)\end{array}$ & $\begin{array}{l}62.62 \\
( \pm 9.93)\end{array}$ & $\begin{array}{l}64.70 \\
( \pm 8.81)\end{array}$ & $\begin{array}{l}61.44 \\
( \pm 8.87)\end{array}$ \\
\hline
\end{tabular}

Abbreviation: $\mathrm{N}$ = total number of enrolled subjects; $\mathrm{n}=$ number of subjects in each group; SD = Standard Deviation. 


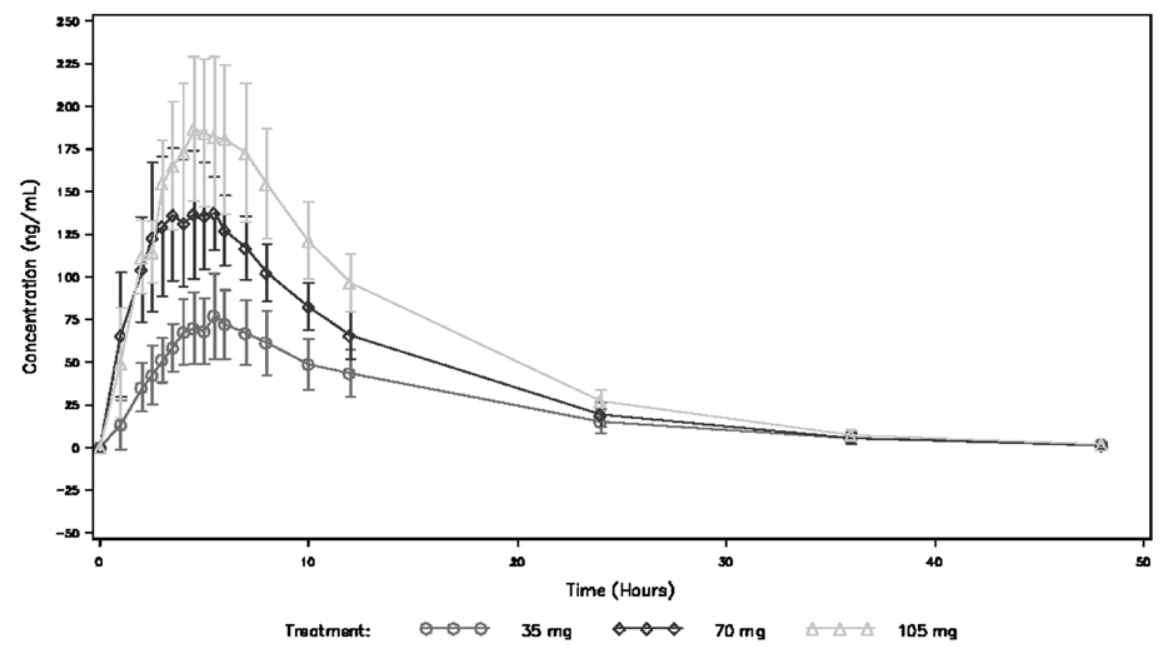

Fig. 1 Trimetazidine plasma concentration (mean \pm SD) vs. time profile following administration of 35,70 , or 105 mg trimetazidine to healthy subjects (linear scale). Assessment of linearity.

- Table 2 Summary of pharmacokinetic parameters following administration of 35,70 or $105 \mathrm{mg}$ trimetazidine to healthy subjects $(\mathrm{N}=18)$ mean $( \pm \mathrm{SD})$.

\begin{tabular}{|l|l|l|l|}
\hline $\begin{array}{l}\text { PK } \\
\text { Parameter }\end{array}$ & $\mathbf{3 5 ~} \mathbf{m g}(\mathbf{n}=\mathbf{6})$ & $\mathbf{7 0 ~} \mathbf{m g} \mathbf{( n = 6 )}$ & $\begin{array}{l}\mathbf{1 0 5} \mathbf{~ m g} \\
\mathbf{( n = 6 )}\end{array}$ \\
\hline $\mathrm{C}_{\max }\left(\mathrm{ng} \mathrm{mL}^{-1}\right)$ & $\begin{array}{l}79.32 \\
( \pm 23.08)\end{array}$ & $\begin{array}{l}153.17 \\
( \pm 32.53)\end{array}$ & $\begin{array}{l}199.67 \\
( \pm 42.5)\end{array}$ \\
\hline $\mathrm{T}_{\max }(\mathrm{h})$ & $5.42( \pm 0.49)$ & $4.51( \pm 1.27)$ & $4.57( \pm 0.96)$ \\
\hline $\mathrm{t}_{1 / 2}(\mathrm{~h})$ & $7.75( \pm 1.62)$ & $6.40( \pm 1.23)$ & $6.50( \pm 1.18)$ \\
\hline $\mathrm{AUC}_{(0-\mathrm{t})}(\mathrm{ng} \cdot \mathrm{h}$ & 1090.09 & 1822.18 & 2480.80 \\
$\left.\mathrm{~mL}^{-1}\right)$ & $( \pm 353.01)$ & $( \pm 278.57)$ & $( \pm 345.88)$ \\
\hline $\mathrm{AUC}_{(0-\text {-inf) }}(\mathrm{ng} \cdot \mathrm{h}$ & 1116.89 & 1838.59 & 2504.84 \\
$\left.\mathrm{~mL}^{-1}\right)$ & $( \pm 378.35)$ & $( \pm 284.50)$ & $( \pm 348.35)$ \\
\hline $\mathrm{CL}_{\mathrm{F}}\left(\mathrm{L} \cdot \mathrm{h}^{-1}\right)$ & $33.69( \pm 8.51)$ & $38.85( \pm 6.15)$ & $42.74( \pm 7.10)$ \\
\hline $\mathrm{CL}_{\mathrm{R}}\left(\mathrm{L} \cdot \mathrm{h}^{-1}\right)$ & $13.70( \pm 2.24)$ & $14.80( \pm 5.91)$ & $19.58( \pm 6.24)$ \\
\hline \multicolumn{2}{|l|}{$\mathrm{Abbreviation:} \mathrm{AUC=Area} \mathrm{under} \mathrm{the} \mathrm{curve;} \mathrm{N}=$ total number of } \\
subjects; SD= standard deviation, $\mathrm{n}=$ number of subjects in the \\
group.
\end{tabular}

Following attainment of $C_{\max }$, the plasma concentration-time profile declined in a broadly mono-exponential fashion with a mean $\mathrm{t}_{1 / 2}$ which was similar in each of the dose groups ranging from 6.40 to $7.75 \mathrm{~h}$. An increase in total exposure $\left(\mathrm{AUC}_{(0 \text {-inf) }}\right)[1116.897$ ( \pm 378.35$), 1838.39( \pm 284.50)$, and $2504.845( \pm 348.35) \mathrm{ng} . \mathrm{h}$ $\mathrm{mL}^{-1}$, respectively] was observed with increasing dose. $\mathrm{CL}_{R}$ was increased in an apparently dose-dependent manner [3.70 $( \pm 2.24)$, $14.80( \pm 5.91)$, and $19.58( \pm 6.24) L \cdot h^{-1}$, respectively] ( Table 2$)$. A concomitant increase in the apparent $C L$ following oral administration $(C L / F)$ was also observed [33.69 ( \pm 8.51$), 38.85( \pm 6.15)$, and $42.74( \pm 7.10) \mathrm{L} \cdot \mathrm{h}^{-1}$, respectively].

Effect of a single dose $(35,70$, and $105 \mathrm{mg})$ of TMZ-modified release on the PK parameters $A \cup C_{(0-\text { inf })}$, $A \cup C_{(0-t)}$, and $C_{\text {max }}$ was analyzed. The slope estimates for all three parameters were less than 1 , indic-
- Table 3 Statistical analysis of trimetazidine pharmacokinetic parameters for the assessment of linearity (slope estimate and $95 \% \mathrm{Cl})(\mathrm{N}=18)$.

\begin{tabular}{|l|l|}
\hline PK parameter & Slope estimate $(\boldsymbol{\beta}) \mathbf{( 9 5 \%} \mathrm{Cl})$ \\
\hline $\mathrm{AUC}_{(0 \text {-inf) }}\left(\mathrm{ng} \cdot \mathrm{h} \mathrm{mL}^{-1}\right)$ & $0.76(0.54,0.99)$ \\
\hline $\mathrm{AUC}_{(0-\mathrm{t})}\left(\mathrm{ng} \cdot \mathrm{h} \mathrm{mL}^{-1}\right)$ & $0.77(0.56,0.99)$ \\
\hline $\mathrm{C}_{\max }\left(\mathrm{ng} \mathrm{mL} \mathrm{mL}^{-1}\right)$ & $0.87(0.60,1.13)$ \\
\hline \multicolumn{2}{|l|}{ Dose Range $=35 \mathrm{mg}(\mathrm{n}=6), 70 \mathrm{mg}(\mathrm{n}=6)$, and $105 \mathrm{mg}(\mathrm{n}=6) ;$} \\
Abbreviation: $\mathrm{AUC}=$ Area Under the Curve; $\mathrm{Cl}=$ Confidence Interval \\
\hline
\end{tabular}

ating that a less than dose-proportional increase in systemic exposure was observed with increasing dose ( $\triangleright$ Table 3 ). The corresponding $95 \% \mathrm{Cl}$ of the slope for the AUC parameters excluded 1, indicating that the deviation from dose-proportionality is statistically significant. Conversely, the corresponding $95 \% \mathrm{Cl}$ of the slope for $C_{\max }$ included 1 , indicating that the less than dose-proportional increase in $C_{\max }$ was not statistically significant. Taken together, these results showed a non-linear PK for a single ascending dose of $\mathrm{TMZ}$ in healthy subjects.

\section{Safety results}

There was no notable change in biochemistry and hematology parameters of the subjects in the study (data not shown). Changes in vital signs from screening were small and there were no differences among the groups in the study (data not shown). There were no clinically significant changes from screening for any subject in the study with respect to ECG findings (data not shown). Overall, the incidence of treatment-emergent adverse events (TEAE) was low. Among the 18 subjects in the study, 7 subjects (38.9\%) experienced a total of $10 \mathrm{AEs}$ during the study. Of these $10 \mathrm{AEs}$, 9 were TEAEs. All TEAEs reported were mild. Three of the nine TEAEs were considered related to the study drug by the investigator and all TEAEs were resolved ( $\triangleright$ Table 4 ). The most common TEAE reported in the study was oral herpes (infections and infestations SOC, two subjects). Three TEAEs (upper abdominal pain, headache, and agita- 
- Table 4 Treatment-emergent adverse events by system organ class, preferred term, and causality by groups ( $N=18)$.

\begin{tabular}{|c|c|c|c|c|}
\hline System Organ Class Preferred Term & Causality & $35 \mathrm{mg}(\mathrm{n}=6) \mathrm{n}(\%), \# E$ & $70 \mathrm{mg}(\mathrm{n}=6) \mathrm{n}(\%), \# E$ & $105 \mathrm{mg}(\mathrm{n}=6) \mathrm{n}(\%), \# E$ \\
\hline \multicolumn{5}{|l|}{ Gastrointestinal disorders } \\
\hline Abdominal pain (upper) & Related & $1(16.7 \%), 1$ & 0 & 0 \\
\hline \multicolumn{5}{|c|}{ General disorders and administration site conditions } \\
\hline Injection site pain & Not related & 0 & 0 & $1(16.7 \%), 1$ \\
\hline \multicolumn{5}{|l|}{ Infections and infestations } \\
\hline Oral herpes & Not related & $1(16.7 \%), 1$ & 0 & $1(16.7 \%), 1$ \\
\hline \multicolumn{5}{|l|}{ Nervous system disorders } \\
\hline Headache & Related & 0 & 0 & $1(16.7 \%), 1$ \\
\hline Sciatica & Not related & 0 & $1(16.7 \%) 1$ & 0 \\
\hline \multicolumn{5}{|l|}{ Psychiatric disorders } \\
\hline Agitation & Related & $1(16.7 \%), 1$ & 0 & 0 \\
\hline \multicolumn{5}{|c|}{ Respiratory, thoracic, and mediastinal disorders } \\
\hline Cough & Not related & 0 & 0 & 1 (16.7\%), 1 \\
\hline Oropharyngeal pain & Not related & 0 & 1 (16.7\%), 1 & 0 \\
\hline
\end{tabular}

tion) in three subjects were considered related to study drug by the investigator in the study. During the study, no fatal outcomes were observed. There were no severe and no serious adverse event (SAEs) reported in the study. No subject discontinued due to $A E$ from the study. Thus, single-dosing of 35,70 , and $105 \mathrm{mg}$ strengths of TMZ-modified release was well-tolerated by the healthy subjects in the study.

\section{Discussion}

In this single ascending dose study, pharmacokinetic parameters after administration of $35 \mathrm{mg}, 70 \mathrm{mg}$, and $105 \mathrm{mg}$ TMZ-modified release were evaluated in healthy subjects. A less than dose-proportional increase in $A \cup C_{(0-\text { inf })}, A \cup C_{(0-t)}$, and $C_{\max }$ was noted. A dosedependent increase in $C_{R}$ and $C L / F$ after single dose administration was observed. Statistical analysis of linearity confirmed that the less than dose-proportional increase in $A \cup C_{(0-i n f)}$ and $A U C_{(0-t)}$ was significant, indicating that the pharmacokinetics of TMZ-modified release is dose dependent over the range of 35 to $105 \mathrm{mg}$. It may be due to an increase in $\mathrm{CL}_{R}$ with increasing dose. Taken together, our results suggest that TMZ-modified release follow a nonlinear pharmacokinetics in human subjects. In addition, the TMZmodified release was well tolerated in all dose groups. No new or unexpected safety concerns were identified during the study.

To our knowledge, this is the first single ascending dose to evaluate the PK of TMZ-modified release in healthy subjects. No phase I study has been performed for TMZ-modified release which determined the linearity of TMZ-modified release after the single ascending dose. However, a few investigators have reported different PK characteristics of TMZ-modified release. In this study, mean $C_{\max }$ of $79.32( \pm 23.08) \mathrm{ng} \mathrm{mL}^{-1}$ was observed with a single dose of $35 \mathrm{mg}$ TMZ-modified release. This result is in line with a previous study by Ozbay et al that reported a median $C_{\max }$ of $63.1( \pm 17.1) \mathrm{ng} \mathrm{mL}-1$ with TMZ [8]. In addition, the median $\mathrm{T}_{\max }$ of $5 \mathrm{~h}$ reported previously in healthy subjects taking TMZ-modified release $(35 \mathrm{mg})$ is similar to results obtained in our study $(5.42 \mathrm{~h})$ [8]. Moreover, the mean $\mathrm{AUC}_{(0-\text { inf })}$ reported in this study was $1116.89( \pm 378.35) \mathrm{ng} . \mathrm{h}$ $\mathrm{mL}^{-1}$ as compared to $793.4( \pm 249.0) \mathrm{ng}$. $\mathrm{h} \mathrm{mL}^{-1}$ reported by others [8]. In addition, total body clearance of TMZ in this study [33.69 $\left.( \pm 8.51) \mathrm{L} \cdot \mathrm{h}^{-1}\right]$ was found comparable to other studies [25.2 $( \pm 4.5)$ $\mathrm{L} \mathrm{h}^{-1}$ ] [3]. Of note, the comparison of the study results to other studies should be done with caution due to the differences in study designs and/or subject demographics.

A few clinical trials have evaluated the safety profile of TMZ in humans. However, for the first time, we conducted a single ascending dose study that included a dose of $105 \mathrm{mg}$, three times more than the recommended dose. No SAE, death or discontinuation due to AEs was observed at any dose in this study, suggesting that a single dose of TMZ-modified release is well tolerated in healthy subjects, even at a dose three times higher than the recommended dose. Only a few TEAE were observed in this study which were mild to moderate in nature and in line with other published studies [9]. Only one case of each of upper abdominal pain, headache, and agitation in three subjects was observed. These AE were considered related to study drug by the investigator. However, in other studies gastric or esophageal burning, muscular cramps, dizziness, effort induced discomfort, depression, sedation, and/or drowsiness, palpitations, visual disturbances, anorexia and hyperorexia have been reported more frequently. TMZ has also been shown to induce parkinsonism, gait disorders and tremor as well. However, the benefits of TMZ therapy continue to outweigh the risks in patients with angina pectoris [5]. Few study limitations should be mentioned. The study was designed as an open-label study rather than a blind placebo-controlled trial. Moreover, the study was conducted with a single-dose and was also limited by the small sample size. Therefore, interpretations of treatment-related AEs should keep this study design in mind.

Only 6 subjects were recruited for each dose regimen. Thus, individual differences in PK parameters may have led to non-linear PK. However, we have taken the blood samples for measurement of PK parameters at short time intervals and included only healthy subjects. We believe these two factors mitigated the effect of small 
sample size. Moreover, it was a single ascending dose study to assess the linearity of PK of trimetazidine in accordance with the standard guidelines which suggest a small sample size for single ascending dose study. A detailed population pharmacokinetic analysis can be performed using the data obtained from this study to assess effect of individual differences and small sample size. However, it is beyond the scope of this study. Furthermore, number of females was not similar among all three groups (50-100\%). AUC could be different for male and female and could be a reason for the less than dose-proportional increase in $\mathrm{AUC}_{(0 \text {-inf })}, \mathrm{AUC}_{(0-\mathrm{t})}$, and $C_{\text {max }}$. Of note, all subjects in the $35 \mathrm{mg}$ treatment group were female which might be a reason for higher $A U C_{(0-i n f)}, A U C_{(0-t)}$, and $C_{\max }$ in this group. However, it has been reported that gender does not affect clinical efficacy of trimetazidine [10]. In addition, it has also been reported in the literature that except for a few drugs, gender-related difference in the pharmacokinetics does not lead to significant effect on clinical efficacy of the drugs [11]. Furthermore, this study was designed according to standard guidelines for PK studies. Therefore, we did not perform any sub-group analysis in this study including effect of gender difference among various dose groups on the linearity of PK of trimetazidine.

\section{Conclusions}

Results of this study fills the gap in the data regarding PK parameters of TMZ-modified release. Our results showed a non-linear PK of TMZ-modified release in human subjects. In addition, it was welltolerated, and no major safety issue was reported. Hence, our study provides adequate preliminary data on dose, safety, and tolerability of TMZ-modified release. The CHMP has requested to conduct pharmacokinetic study in special population including elderly and renal-impaired patients. However, clinical trial data on the linearity of PK of trimetazidine was not available. Thus, as a first step, we conducted the current study to assess linearity of PK of trimetazidine in healthy subjects. Since results from this study showed a non-linear PK of trimetazidine, we designed another multiple-dose study evaluating 'effect of age and glomerular filtration rate on the pharmacokinetics and safety of trimetazidine. Results from the multiple-dose dose study have been published elsewhere.

\section{Disclosures}

Thomas Koernicke is an employee of the PAREXEL International $\mathrm{GmbH}$, Germany. Abdus Samad, Deepa Arora, and Shashank Jain are employees of Lupin Limited, India. Sigal Kaplan is an employee of Teva Pharmaceutical Industries Ltd, Israel. Mónika Domahidy is an employee of Gedeon Richter Plc., Hungary. Hanka de Voogd is an employee of Mylan EPD, The Netherlands. Stella Böhmert is an employee of Sandoz International GmbH, Germany. Rita Silveira Ramos is an employee of Generis ${ }^{\circledR}$ Farmacêutica, Portugal.

\section{Acknowledgement}

We thank Olga Mariscal Fernandez (CINFA International, Spain) and Irina Badoi (Albogen, Romania) in designing the study and analyzing the results. We also thank Anirudh Sahoo (Mylan, India) for his help in editing and reviewing the manuscript. This study was funded by a consortium of companies including Actavis Group PTC ehf., Alvogen IPCo S.a.r.I., Chemical Works of Gedeon Richter Plc., Generis Farmacêutica, S.A., Labesfal Genéricos S.A., Laboratorios Cinfa, S.A., Hexal AG (Sandoz Group), Lupin (Europe) Limited, Mylan S.A.S., and Teva Pharmaceuticals Europe B.V.

\section{Conflict of Interest}

Abdus Samad, Deepa Arora, and Shashank Jain are employees of Lupin Limited, India. Sigal Kaplan is an employee of Teva Pharmaceutical Industries Ltd, Israel. Mónika Domahidy is an employee of Gedeon Richter Plc., Hungary. Hanka de Voogd is an employee of Mylan EPD, The Netherlands. Stella Böhmert is an employee of Sandoz International GmbH, Germany. Rita Silveira Ramos is an employee of Generis ${ }^{\circledR}$ Farmacêutica, Portugal.

\section{References}

[1] Les Laboratoiros Servier France. VASTAREL 35 mg, modified-release film-coated tablet. 2012

[2] Jackson PJ, Brownsill RD, Taylor AR et al. Identification of trimetazidine metabolites in human urine and plasma. Xenobiotica 1996; 26 : 221-228. doi:10.3109/00498259609046702

[3] Barré ], Ledudal P, Oosterhuis B et al. Pharmacokinetic profile of a modified release formulation of trimetazidine (TMZ MR $35 \mathrm{mg}$ ) in the elderly and patients with renal failure. Biopharm Drug Dispos 2003; 24: 159-164. doi:10.1002/bdd.350

[4] Thadani U. Modified-release formulation of trimetazidine for exceptional control of angina pectoris: Fact or fiction. Am J Cardiovasc Drugs 2005; 5: 331-334. doi:10.2165/00129784-200505050-00006

[5] European Medicines Agency (EMA). Assessment Report for trimetazidine containing medicinal products 2012; 44, https://www.ema. europa.eu/en/documents/referral/trimetazidine-article-31-referralassessment-report_en.pdf

[6] Nenchev N, Skopek J, Arora D et al. Effect of age and renal impairment on the pharmacokinetics and safety of trimetazidine: An open-label multiple-dose study. Drug Dev Res 2020; ddr. 21654. doi:10.1002/ ddr.21654

[7] Levey AS, Bosch JP, Lewis JB et al. A more accurate method to estimate glomerular filtration rate from serum creatinine: A new prediction equation. Ann Intern Med 1999; 130: 461-470. doi:10.7326/00034819-130-6-199903160-00002

[8] Ozbay L, Unal DO, Erol D. Food effect on bioavailability of modifiedrelease trimetazidine tablets. J Clin Pharmacol 2012; 52: 1535-1539. doi:10.1177/0091270011422813

[9] Dézsi CA. Trimetazidine in Practice. Am J Ther 2016; 23: e871-e879. doi:10.1097/MJT.0000000000000180

[10] Vasiuk IA, Shal'nova SA, Shkol'nik EL, Kulikov KG. The (PRIMA) Study. Comparison of clinical effect of trimetazidine MR in men and women. Kardiologiia 2011; 51: 11-15

[11] Meibohm B, Beierle I, Derendorf H. How Important Are Gender Differences in Pharmacokinetics? Clin Pharmacokinet 2002; 41: 329-342. doi:10.2165/00003088-200241050-00002 